\title{
O Futuro do Turismo de Santa Catarina - Previsões entre 2007 e 2011
}

\section{The Future of Tourism from Santa Catarina - Previsions between 2007 and 2011}

\author{
Fernando A. Ribeiro Serra ${ }^{1}$ \\ Eliza Bianchini Dallanhol Locks² \\ Graciella Martignago ${ }^{3}$ \\ Solange Evangelista ${ }^{4}$ \\ Stefano Palumbo ${ }^{5}$
}

\section{Resumo}

Este artigo apresenta o resultado da primeira parte de uma pesquisa Delphi sobre "O Futuro do Turismo em Santa Catarina” realizada com painel de especialistas do setor, composto por empresários e acadêmicos. O objetivo fundamental foi o de identificar o cenário prospectivo mais provável de forma a orientar proposições e ações para atuação diante do cenário previsto. A metodologia considerou a escolha preliminar de 36 especialistas, segundo onze tópicos para análise, dos quais foram selecionados 12 especialistas para aplicação das rodadas de questionário. O resultado da pesquisa Delphi foi debatido entre os especialistas e debatedores em mesmo número, em três sessões principais que compuseram a pesquisa: demanda e oferta turística; a economia do turismo catarinense; as ações.

Palavras-chave: pesquisa Delphi; cenários; tendências em turismo; estratégia.

\begin{abstract}
This article presents the results of the first part of a Delphi research about "The Future of Tourism from Santa Catarina" with specialists from the sector - entrepreneurs and academics. The main purpose was to identify the most probable prospective scenario in order to orient propositions and action to act over the scenario. The methodology considered the preliminary choice of 36 specialists, under 12 analysis topics, from which 12 specialists were selected to answer it in rounds. The Delphi research result was debated among the specialists and debaters in a seminar. Three sections composed the research and the seminar: touristy offer and demand; Santa Catarina tourism economy; actions.
\end{abstract}

Keywords: Delphi research; scenaries; tendencies in tourism; strategy.

\footnotetext{
${ }^{1}$ Doutor em Engenharia pela PUC-Rio, dirige a Unisul Business School em Florianópolis, é professor do Programa de Pós-graduação em Administração da Universidade do Sul de Santa Catarina (Unisul). E-mail: fernandoserra@unisul.br

${ }^{2}$ Mestre em Economia e Gestão do Turismo pelo CISETH da Universitá CáFoscari na Itália, é coordenadora do curso de Turismo da Universidade do Sul de Santa Catarina (Unisul).E-mail: eliza@unisul.br

${ }^{3}$ Mestre em Engenharia da Produção pela UFSC, é professora da Unisul Business School em Florianópolis. Email: graciella.martignago@unisul.br

${ }^{4}$ Doutora em Engenharia da Produção pela UFSC, é professora da Unisul Business School em Florianópolis. Email: solange@unisul.br

${ }^{5}$ Sociólogo, é diretor da S3 Studium em Roma. E-mail: spalumbo@s3studium.it
} 


\section{Introdução}

Este trabalho apresenta as tendências apresentadas da pesquisa Delphi “O Futuro do Turismo em Santa Catarina - Previsões entre 2007 e 2011”, segundo a visão de especialistas compostos por empresários e acadêmicos do setor. O principal objetivo desta etapa do trabalho, que conta ainda com um Fórum para debate entre os especialistas e debatedores e, a consolidação do relatório com propostas, é que as tendências identificadas pelos especialistas, criam um cenário prospectivo que servirá como referencia para orientar proposições e ações para atuar sobre ele, de forma a aproveitar ou combater certas tendências numa possível atuação conjunta de governo estadual, organizações e sociedade civil.

Para elaboração do cenário foi utilizada a técnica Delphi, na qual especialistas respondem exaustivamente rodadas de questionários, em busca de consenso de suas opiniões sobre eventos futuros. No caso desta pesquisa Delphi, o consenso foi alcançado na segunda rodada de questionários.

Neste trabalho são apresentados os principais resultados da pesquisa, a seguir a apresentação do referencial teórico que contempla aspectos fundamentais sobre cenários prospectivos e sobre a técnica Delphi, além dos aspectos metodológicos relevantes da pesquisa.

\section{Referencial Teórico}

\subsection{O uso de cenários no planejamento}

Como, de modo geral, o futuro é incerto, o uso de cenários pode ser uma ferramenta poderosa de planejamento, um apoio fundamental para a tomada de decisões estratégicas (SERRA TORRES e TORRES, 2002). O uso de cenários em planejamento se notabilizou pelo uso da técnica pela Shell, como ferramenta na qual a técnica Delphi também pode ser utilizada. Segundo Porter (1986, p. 243), “cenários são visões parciais e internamente consistentes de como o mundo será no futuro e que podem ser escolhidas de modo a limitar o conjunto de circunstâncias que podem vir a ocorrer”.

A diferença fundamental entre o planejamento de cenários e as previsões está no fato de que o planejamento de cenários aceita a incerteza. Desta forma, o planejamento de cenários demanda o desenvolvimento de um conjunto de alternativas de futuro e a percepção dos 
diferentes caminhos que conduzem às diferentes alternativas de futuro (CORNELIUS, VAN DE PUTTE e ROMANI, 2005).

\subsection{O método Delphi no desenvolvimento de cenários prospectivos}

No Brasil, além do estudo em questão (UNISUL e S3 STUDIUM, 2006), diversos outros Delphi tem sido realizados para a elaboração de cenários prospectivos e outros trabalhos (S3 STUDIUM, 2002; FISCHER e ALBUQUERQUE, 2001; GIOVINAZZO e FISCHMANN, 2000; SANTOS, 2001).

A técnica Delphi, conforme Linstone e Turoff (1975, p. 3), é um “método de estruturação de um processo de comunicação grupal, que é efetivo para permitir a um grupo de indivíduos, como um todo, tratar um problema complexo".

No método Delphi, um grupo de especialistas selecionados é questionado sobre acontecimentos futuros em sucessivas rodadas anônimas e com o máximo de autonomia dos participantes, com o objetivo de alcançar consenso (LANDETA, 1999; LINSTONE e TUROFF, 1975; GODET, 1993). Esta pesquisa se utiliza tradicionalmente de Correio, porém atualmente vem sendo utilizada cada vez mais a Internet para este fim (VERGARA, 2005; GIOVINAZZO e FISCHMANN, 2000).

Os resultados, entretanto, dependem fortemente da qualidade do questionário e da seleção dos especialistas (GODET, 1993).

Embora o método preveja várias etapas sucessivas de questionários, muitas vezes pode se limitar a duas rodadas, sem afetar com isto a qualidade o que já foi demonstrado em muitos trabalhos (VERGARA, 2005).

Os questionários sucessivos são utilizados para reduzir o "espaço interquartil”, que é quanto se desvia da opinião do conjunto (mediana), a opinião de um especialista. O objetivo do primeiro questionário é, então, calcular este desvio. No segundo questionário, as respostas com a opinião de cada um dos especialistas, derivadas do primeiro questionário, recebem um tratamento e são devolvidas aos especialistas, dessa vez em forma de perguntas fechadas, onde cada participante deverá apenas concordar ou discordar da opinião apresentada, para que se obtenha consenso nos resultados e geração de conhecimento sobre o tema em questão. Caso seja necessária mais uma, ou mais consultas, espera-se um maior consenso sobre o tema (GODET, 1993, LANDETA, 1999). 
O Quadro 1, apresentado a seguir, resume as etapas usuais de uma pesquisa com o método Delphi.

\section{Quadro 1 - Etapas usuais do método Delphi}

\begin{tabular}{|l|l|l|}
\hline \multicolumn{1}{|c|}{ Etapa } & \multicolumn{1}{|c|}{ Descrição } & \multicolumn{1}{c|}{ Observações } \\
\hline $\begin{array}{l}\text { Definição do } \\
\text { problema }\end{array}$ & $\begin{array}{l}\text { Definir com precisão o escopo da } \\
\text { investigação de forma a possibilitar } \\
\text { a seleção e elucidação dos } \\
\text { especialistas. }\end{array}$ & $\begin{array}{l}\text { Observar na elaboração do questionário: } \\
\text { perguntas precisas, quantificáveis (pelo menos } \\
\text { sobre possibilidades ou dados), e independentes } \\
\text { (uma questão não necessariamente tem que } \\
\text { aparecer em outro questionário) }\end{array}$ \\
\hline $\begin{array}{l}\text { Escolha dos } \\
\text { especialistas }\end{array}$ & $\begin{array}{l}\text { Escolher os especialistas em } \\
\text { função da sua capacidade de } \\
\text { contribuir para imaginar o futuro } \\
\text { pelos conhecimentos que possui do } \\
\text { tema, independentemente de } \\
\text { títulos, função ou nível } \\
\text { hierárquico. }\end{array}$ & $\begin{array}{l}\text { As opiniões devem ser recolhidas anonimamente } \\
\text { por via postal ou eletrônica, garantindo, assim, a } \\
\text { independência dos especialistas. }\end{array}$ \\
\hline $\begin{array}{l}\text { Elaboração e } \\
\text { lançamento dos } \\
\text { questionários }\end{array}$ & $\begin{array}{l}\text { Elaborar os questionários, } \\
\text { procurando facilitar a resposta } \\
\text { pelos especialistas. Procurar que as } \\
\text { respostas sejam quantificadas e } \\
\text { ponderadas. }\end{array}$ & $\begin{array}{l}\text { apresentar uma probabilidade e prioridade de } \\
\text { ocorrência, que datas sejam expressas, } \\
\text { informações, dados etc. }\end{array}$ \\
\hline $\begin{array}{l}\text { Desenvolvimento e } \\
\text { exploração dos } \\
\text { resultados }\end{array}$ & $\begin{array}{l}\text { Enviar o questionário aos } \\
\text { especialistas, mais que 7. Alguns } \\
\text { apontam como pelo menos 25. }\end{array}$ & $\begin{array}{l}\text { Enviar carta de apresentação do trabalho com } \\
\text { seus objetivos, prazo para resposta e garantia de } \\
\text { anonimato. } \\
\text { A partir do segundo questionário, informar aos } \\
\text { especialistas dos resultados e solicitar nova } \\
\text { resposta, justificando caso seja muito divergente. }\end{array}$ \\
\hline
\end{tabular}

Fonte: Adaptado de Godet (1993) e Landeta (1999).

\section{Metodologia}

Quanto aos fins, a pesquisa “O Futuro do Turismo em Santa Catarina” é exploratória, pois visa apresentar um cenário prospectivo. Quanto aos meios, como foi mencionado, utiliza-se do método Delphi. Vale observar que a pesquisa inclui para a elaboração do cenário preliminar a realização de um Fórum para debate dos resultados, com a presença dos especialistas e de debatedores, para posterior elaboração do relatório final da pesquisa. Este trabalho apresenta os resultados do Delphi, somente.

O objetivo do projeto foi a construção de um cenário previsional sobre a evolução do setor de turismo em Santa Catarina (SC), para o período 2007-2011. O cenário se valeu de uma variante do método Delphi. 
A característica peculiar do método é a consulta - de maneira rigorosamente individualizada e anônima - de um grupo de especialistas, com o objetivo de obter previsões baseadas na convergência das opiniões sobre o futuro do tema escolhido. Para este projeto decidiu-se utilizar um processo de consulta em duas fases de um grupo interdisciplinar de doze especialistas.

As principais limitações do estudo devem-se ao próprio método pelo custo, duração da pesquisa e pelo fato de ser mais intuitivo que racional. $\mathrm{O}$ fato de considerar o consenso, deixa de fora opiniões que, embora divergentes, podem ser relevantes.

A pesquisa foi iniciada em maio e finalizada em setembro de 2006, tendo sido realizada com base nas seguintes etapas:

1) análise preliminar do tema: o tema foi examinado para identificar as dimensões de análise, as disciplinas envolvidas no problema da pesquisa e elaborar uma lista de possíveis especialistas, escolhidos entre os mais competentes e reconhecidos; 2) elaboração das perguntas: com base nos resultados de dinâmica de focus group, a equipe técnica elaborou um documento de base e um questionário com perguntas abertas, sobre os seguintes temas: desempenho econômico do setor; diferenças regionais no desempenho; investimentos nacionais e estrangeiros; geração de emprego; gasto médio diário; principais emissores de turistas; fluxos de turistas; destinos concorrentes; sazonalidade do turismo; perfil do turista; impactos sócio-econômicos e ambientais; atrativos turísticos de Santa Catarina; meios de hospedagem; evolução das empresas turísticas; marketing empresarial; políticas públicas para o setor; oportunidades e ameaças externas; pontos de força e de fraqueza do setor; 3) respostas dos especialistas por escrito e, em alguns casos, foi feita uma complementação por meio de e entrevistas diretas; 4) consolidação das respostas e segunda consulta aos especialistas: as respostas foram reunidas e reordenadas por temas e na seqüência submetidas, novamente, aos mesmos especialistas, em um segundo questionário com perguntas pré-estabelecidas. Com isso, obteve-se o consenso ou o dissenso sobre cada uma das hipóteses surgidas durante a primeira consulta. É importante destacar que os especialistas não sabiam quem fazia parte do painel durante toda a realização da pesquisa; 5) elaboração dos resultados: a pesquisa foi concluída com a elaboração das respostas, a seleção das hipóteses aceitáveis (aquelas que receberam ao menos oito indicações consensuadas entre os doze especialistas), a análise dos resultados, a definição dos temas a serem tratados no relatório e, por fim, a redação do texto. 


\section{Apresentação dos Resultados}

\subsection{As tendências mundiais e brasileiras do turismo}

O dado mais importante dos próximos anos para o turismo será o aumento no volume de viajantes. Conseqüentemente, o capital envolvido na atividade turística estará crescendo até o final do decênio. Isso será um fenômeno mundial.

Junto com a demanda, crescerá a oferta e a possibilidade de acessá-la. No turismo internacional as distâncias se tornarão cada vez menos importantes.

A sazonalidade do turismo não deixará de representar um problema essencial do setor, estimulando uma enorme concorrência. Os eventos serão uma solução para equilibrar um pouco a sazonalidade.

Além das possíveis políticas de oferta, nos próximos anos, o gasto dos turistas no Brasil será influenciado pelo câmbio do Real com moedas mais fortes.

Os turistas também serão, cada vez mais, exigentes e conscientes na escolha de seus destinos. Apesar do crescimento do número de turistas no mundo, será difícil atraí-los.

A natureza continuará sendo uma das principais razões para a existência do turismo. Cada vez mais, todos os projetos serão “ecologicamente corretos" valorizando e respeitando o meio ambiente.

Um grande investimento será favorecido pela flexibilização da legislação federal proporcionando vantagem a setores como transporte aéreo e infra-estrutura aeroportuária, transporte marítimo e fluvial e infra-estrutura portuária.

O desenvolvimento de uma oferta de nível internacional se tornará imediatamente um instrumento de política cultural interna, porque os eventos culturais utilizados como atrativos para os turistas representarão também uma oferta cultural muito elevada e prestigiada para a população local. 
O percentual do turismo mundial que escolherá o Brasil como destino dependerá das políticas de desenvolvimento do turismo experiencial: turismo de convenções; turismo científico; turismo cultural; turismo ecológico; turismo patrimonial.

No Brasil, os investimentos mais significativos na área hoteleira, até 2011, serão aplicados: tanto em pousadas com estrutura profissional; quanto em redes de pequeno e grande porte. SC, em particular, será um destino relevante para esses investimentos.

Nos próximos anos, a profissionalização será indispensável, não somente para o desenvolvimento, mas para a sobrevivência das atividades turísticas, enquanto a tecnologia e a comunicação serão fatores de diferenciação.

\subsection{Demanda e oferta turística}

\subsubsection{A concorrência dos destinos}

A concorrência internacional para SC será muito diferenciada em relação aos motivos da visita. Será necessário identificar os concorrentes e escolher um posicionamento adequado para o turismo catarinense. Na perspectiva internacional, a participação de SC no mercado turístico crescerá porque o Estado aumentará a qualidade da oferta ambiental e cultural.

São Paulo continuará a ser uma atração ímpar no contexto brasileiro, baseada na sua unicidade: nos negócios; na academia; nos setores profissionais. O Rio de Janeiro será sempre um destino especial no Brasil e os jogos Pan-americanos, em 2007, trarão novas oportunidades para a cidade. Ambos continuaram a sofrer com a criminalidade.

SC permanecerá como um destino que se diferencia em relação aos outros, com respeito à segurança. As políticas mais agressivas e eficazes dos Estados do NE continuarão atraindo os turistas da Região SE (MG, SP, RJ).

Os turistas dos Estados vizinhos se interessarão pelas possibilidades da oferta turística de SC. O verão será uma ótima opção para quem quer algo diferente, enquanto: as praias gaúchas continuarão ruins (vento e água fria); as paulistas ficarão superlotadas.

Os concorrentes nacionais mais fortes deverão ser o RJ e o NE. No inverno, os concorrentes nacionais mais relevantes de SC serão Campos do Jordão/SP e a Serra Gaúcha/RS. Naquele período, uma vantagem de SC será que nenhum deles têm Litoral e Serra próximos. No caso 
do turismo de negócios, São Paulo continuará sendo o grande destino, e com um significativo incremento, ano a ano.

A chegada de navios nos portos de SC representará uma boa ocasião para as empresas locais venderem produtos e serviços aos turistas.

No nível internacional, os concorrentes mais fortes para atrair o fluxo de turistas americanos e europeus para a região de SC serão a Argentina e o Chile.

Os mais aguerridos concorrentes nacionais na conquista do mercado americano e europeu permanecerão os mesmos da atualidade, ou seja, os destinos do NE. A força do NE será devida à grande proximidade, mas também, aos grandes investimentos de grupos hoteleiros e/ou investidores à procura de novas opções de mercados para os turistas americano e europeu.

\subsubsection{Evolução do turista}

O número de turistas no mundo crescerá de maneira constante, por razões demográficas, econômicas, culturais e pela diminuição dos custos de transporte. É importante evidenciar que, no mundo, a demanda de serviços turísticos de alta qualidade ficará por muitos anos, superior à oferta de bons operadores turísticos.

Haverá um aumento gradativo do turismo em SC, sendo que, a partir de 2010, a expansão será mais significativa devido a um incremento natural da importância do turismo como negócio e como responsabilidade social.

No contexto catarinense, o turista estrangeiro de potencial mais relevante virá de um raio máximo de acerca $2.000 \mathrm{~km}$.

A qualificação do perfil do cliente catarinense se tornará possível aumentando o número de turistas de alta renda proveniente: dos Estados brasileiros mais ricos (SP, RGS, PR, etc.); e dos principais países vizinhos (Argentina, Chile, etc.). Estes dois tipos de emissores garantirão à SC um crescimento elevado e uma melhoria do gasto médio.

A sazonalidade continuará sendo um problema em praticamente todos os destinos turísticos do país e haverá uma evolução gradativa nas regiões turísticas de SC, que deixará o problema 
sem solução até 2011. A sazonalidade permanecerá, devido à falta de políticas na oferta. Acontecerão ações isoladas para amenizar a sazonalidade na região.

Até 2011, o número de turistas estrangeiros para SC crescerá, com um aumento da taxa média de $5 \%$ ao ano. Os emissores internacionais se manterão na mesma ordem atual. Ao superar sua pior crise, a Argentina dobrará o seu fluxo de turistas para SC entre o período considerado, passando a ser o país que mais contribuirá com o desenvolvimento do turismo. O turismo sofrerá os efeitos da evolução do câmbio entre o real e o peso argentino. Haverá um aumento da chegada de turistas estrangeiros provenientes da Europa. O turista alemão continuará gastando mais do que os outros.

O turismo doméstico se incrementará a uma taxa de 4\% ao ano. O turismo interno será propiciado pelo desenvolvimento da infra-estrutura de saneamento básico efetivo nas regiões turísticas (principalmente no litoral com a implantação de emissários oceânicos).

Os Estados que apresentarão um incremento na emissão de turistas para Santa Catarina serão: RS; PR; SP; SC. Os turistas do RS viajarão mais para SC graças à finalização da BR 101 Trecho Sul.

O fluxo de turistas paulistas para SC crescerá bastante até 2011, devido ao grande interesse do paulista nos atrativos de SC. Nos próximos anos, SP passará para ser o segundo emissor de turistas para SC. Atingirá o mínimo de 25\% de participação no fluxo turístico de SC pelo incremento na divulgação do destino.

Haverá uma melhoria no crescimento da renda da população nos próximos 5 anos e, conseqüentemente a população desfrutará mais do turismo, principalmente interno.

Os executivos e profissionais liberais terão maior participação como turistas de SC. Os turistas de nível mais baixo terão um decréscimo (percentual) da sua participação.

O turista predominante em SC será incluído na faixa etária entre os grupos 25 e 60 anos. Aumentará a participação das pessoas com idade média acima de 30 anos interessadas no turismo ecológico-ambiental e, principalmente, cultural.

Os jovens do mundo desenvolvido tenderão a visitar países de alta atração por seu patrimônio natural e cultural. No Brasil e em SC, o fluxo principal dos jovens ficará ligado ao verão. Crescerão os jovens que gostam de aventura e esportes. Sendo um destino universitário, o 
maior aumento da participação será a de um público: de 20 a 30 anos; com perfil de classe média alta; nível educacional superior; de ambos os sexos.

Haverá incremento relevante também do turismo da terceira idade que representará o grupo mais relevante fora de temporada para o turismo em alguns balneários.

A realização de eventos fora de temporada serão mais expressivos na atração de públicos alternativos. Sobretudo o verão em Florianópolis terá, cada vez mais, segmentação. Optarão por SC solteiros e GLS (“Gays, Lésbicas e Simpatizantes). A realização do carnaval GLS, em SC, continuará sendo um grande atrativo para este tipo de turista.

\subsubsection{Os atrativos de Santa Catarina}

Os turistas estrangeiros que entrarem no Brasil pelo Rio ou pela Bahia já terão grande contato com o litoral brasileiro e fazê-los vir até o Sul somente com o atrativo da praia catarinense será um desafio maior. SC alcançará o público internacional (Europa e EUA) graças à criação de uma oferta “casada” com atrativos de outras localidades próximas.

O suporte mais interessante desta estratégia será a combinação Florianópolis e Foz do Iguaçu, atraindo turistas de países ricos.

Os atrativos naturais sejam eles em forma de praia ou de campo, continuarão sendo os mais importantes para o Estado e a melhoria na exploração deles criará uma imagem ainda mais presente e forte. Os maiores atrativos de SC serão aqueles ligados ao mar.

Em função do clima temperado do Estado, outros tipos de turismo (rural, de aventura, de negócios) ganharão mais espaço do que no passado.

Contudo, no futuro próximo, o turismo catarinense mudará, progressivamente, a sua imagem, substituindo o foco sobre "natureza” pelo foco em “ecologia” e “ecoturismo”. A promoção do ecoturismo consentirá à SC valorizar o crescente interesse para a sustentabilidade ambiental das atividades humanas como um valor agregado à experiência turística.

As praias que não tiverem planejamento da infra-estrutura (esgoto, limpeza, falta de água, segurança e doenças) perderão espaço, abrindo possibilidades para a comercialização do turismo: cultural; ambiental (parques, reservas ecológicas, entre outros). 
O sul do Brasil terá em suas características culturais, em seu clima e sua gastronomia um grande diferencial.

Santa Catarina correrá o risco, nos próximos anos, de destruir seu maior “ativo”: a qualidade do seu território. Isto será decorrente: da fraqueza do sistema de saneamento frente à pressão humana durante o verão; do crescimento urbano sem planejamento e sem limites; do desmatamento.

Santa Catarina criará, nos próximos anos, um modelo de turismo baseado na capacidade de unir a natureza ao: ambiente favorável para os negócios; atendimento de nível internacional.

Na América Latina, este modelo turístico não ficará sem concorrentes, porque esta oferta integrada será conquistada pelos destinos: de negócio, tais como: São Paulo, Curitiba ou Santiago do Chile; baseados nos atrativos naturais (como Bahia, Fortaleza e Finta de Leste); fortes na oferta cultural (como Rio de Janeiro, São Paulo e Buenos Aires).

O atrativo que ganhará mais espaço será a qualidade de vida.

Apesar de os principais atrativos turísticos de SC serem naturais, os atrativos culturais serão cada vez mais desenvolvidos. Nos próximos anos, em SC, haverá um crescimento da oferta cultural, sobretudo, no segmento dos parques marinhos e aquários. Ganharão destaque e importância os setores que investirem em: história e roteiros pré-históricos; roteiros religiosos; na valorização da cultura local.

A construção de centros de eventos por todo o Estado ajudará muito o turismo de negócios. O turismo de eventos se desenvolverá em todos seus segmentos: eventos de empresas; congressos nacionais e internacionais; eventos esportivos; eventos religiosos; eventos de música e dança; mostras e manifestações culturais; “parada gay”.

Sem dúvida, o tipo de turista que terá o maior crescimento até 2011 será o turista “experiencial”. E este tipo de turista terá curiosidade e interesse para: a identidade da população local; sua qualidade de vida.

\subsection{A economia do turismo catarinense}

\subsubsection{O desempenho do setor}


A premissa necessária de uma descrição da economia do turismo em Santa Catarina nos anos 2007-2011 é que todas as tendências locais terão uma forte relação com os fenômenos econômicos do continente e do País.

O desempenho do turismo em SC será influenciado, principalmente, pelo cenário econômico nacional e da América do Sul. Será também a continuidade nos projetos turísticos dos governos que manterá o crescimento gradativo do turismo no país.

Em SC, o turismo terá um crescimento constante, mas moderado, porque o Estado terá o problema da sazonalidade. Nos próximos anos haverá em SC uma redução da sazonalidade, que consentirá uma maior concentração de investimentos de resorts e pacotes.

O crescimento será bastante expressivo comparado com outros setores econômicos chegando, até 2011, à média de 6-7\% ao ano. Mas, depois do período considerado, se nada for feito, principalmente no saneamento, haverá queda no setor.

O mercado turístico ligado ao atrativo gastronômico será muito dinâmico, e o turismo local terá grande vantagem ao conectar-se com a gastronomia.

Os pequenos empreendimentos da hotelaria mudarão o próprio direcionamento, superando a tendência de satisfazer uma demanda interna regional pouco exigente e de baixo poder aquisitivo.

Em síntese, até 2011, os segmentos do setor de turismo que terão o melhor desempenho serão: as pousadas; os resorts; a gastronomia; os agroturismos; as agências de organização de eventos; a hotelaria.

Em relação às previsões sobre o desempenho total do turismo, é preciso destacar que haverá relevantes diferenças regionais. A região litorânea do Estado crescerá mais lentamente do que as principais cidades. Esta maior lentidão se concretizará em virtude da sazonalidade mais presente no turismo litorâneo. Então, no litoral crescerá o turismo nas áreas com maior proximidade às principais cidades. O litoral catarinense, de maneira geral, terá até 2011 um crescimento médio com taxa de 5\% ao ano.

O Litoral Norte de SC terá o crescimento mais expressivo. Isso será favorecido pelos investimentos feitos na região, que contribuirão principalmente para a melhoria das vias de acesso (duplicação da BR 101) e pela ação de algumas prefeituras com maior visão de futuro, 
investindo em eventos fora da temporada de verão (como Oktoberfest, Festival de Dança de Joinville, etc).

O Litoral Sul do Estado terá também um bom desempenho graças à duplicação da BR-101. O sul do Estado concentrará os esforços na criação de uma rota turística de caráter cultural/patrimonial. Esta será realizada em parceria com o RS e gerará novas oportunidades para o setor.

O efeito conjunto da realização de obras de saneamento e do lançamento do turismo náutico, com equipamentos adequados, consentirá - em algumas localidades - um crescimento turístico da ordem dos $10 \%$ por ano.

Na Ilha de Santa Catarina também o turismo aumentará, sobretudo porque melhorará a oferta de turismo experiencial (Economia da Experiência).

Florianópolis comparada a outras cidades turísticas, terá uma grande desvantagem geográfica, por estar mais distante da Europa em relação aos demais destinos. Florianópolis terá um crescimento do turismo em torno de $5 \%$ ao ano, assim como Joinville.

A Região Serrana terá um bom crescimento. Isso acontecerá porque aumentará a procura por este destino nas férias de verão. O desenvolvimento turístico da Serra só acontecerá se houver investimentos.

Na região Oeste do Estado crescerão as cidades próximas às novas hidrelétricas.

Graças ao crescimento geral do turismo catarinense, todos os tipos de hospedagem terão um bom desempenho nos próximos cinco anos. Do ponto de vista da composição do segmento, é previsível que a participação no mercado turístico de Santa Catarina será, até 2011: de 80 a 90\% pela hotelaria independente e redes hoteleiras; e de 10 a $20 \%$ pelos meios informais de hospedagem.

Os meios informais de hospedagem (aluguel de casas, casas de amigos, etc) continuarão sendo utilizados, e em medida crescente: este tipo de hospedagem, de fato, crescerá em todo o Estado. Porém, para que os pequenos meios de hospedagem alcancem maior participação no turismo catarinense terão que melhorar sua organização e qualidade.

SC fará parte dos planos de expansão das redes hoteleiras no médio-longo prazo. 
A inserção das redes internacionais ocorrerá apenas em destinos com um fluxo maior de executivos, como Blumenau, Florianópolis e Joinville.

Em relação a este tipo de público-alvo, a estratégia da hotelaria de redes será posicionar-se nos centros das cidades catarinenses, deixando o litoral e as demais regiões turísticas para a hotelaria independente. Seja como for, no longo prazo, as redes hoteleiras internacionais darão um novo formato à oferta turística catarinense, sobretudo mudando a oferta de hotéis de média escala.

Todos os segmentos do setor de turismo gerarão novos empregos. A oferta de empregos dirá respeito, sobretudo, à base da pirâmide profissional, em escala proporcional ao crescimento da oferta de empreendimentos de pequeno porte.

Uma administração profissional será muito importante para o resultado financeiro e a tendência dos empregos no setor turístico. Na área da cultura também, sendo alavancada pelo desenvolvimento turístico, se gerarão mais empregos - e mais qualificados - que no passado. Os novos Cursos de Hotelaria e Turismo, estruturando-se e alcançando um diferencial qualitativo, formarão uma nova geração de profissionais; começando a dar a sua efetiva contribuição dentro de 3 a 4 anos.

Os segmentos do setor de turismo que terão o maior crescimento do emprego até 2011 serão os seguintes: a hotelaria em geral; a pequena hotelaria; a gastronomia em geral; as agências de organização de eventos; os serviços de turismo ecológico; os serviços de turismo patrimonial; a gastronomia de alta qualidade.

O setor de agenciamento de viagens passará por uma grande reformulação em relação ao cenário internacional de corte no comissionamento, unificação das grandes agências de viagens e o avanço da tecnologia da informação e comunicação, possibilitando o acesso direto entre consumidores e fornecedores.

\subsubsection{Os recursos do turismo}

No contexto catarinense, a tendência do crescimento dos investimentos internos no âmbito turístico estará muito atrelada, nos próximos anos: à estabilidade e ao crescimento econômico do País; ao potencial turístico do Estado. 
As tendências ao investimento em SC, serão influenciadas pela formulação de regras claras e pela política que o novo governo brasileiro irá colocar em prática.

SC terá dificuldade na atração de capitais estrangeiros, mas não ficará sem melhorias. A tendência geral dos investimentos será majoritariamente de empreendedores locais ou regionais. O caráter destes investimentos será muito mais reativo, em face de algumas oportunidades de negócios decorrentes de ações para a regionalização do turismo interno e centrado em pequenos negócios. Os investimentos serão endereçados, predominantemente, na faixa litorânea.

A evolução do nível de gasto médio ficará similar à evolução da renda: dos brasileiros; dos vizinhos estrangeiros. O gasto médio por turista continuará, no curto prazo, evoluindo da mesma forma que o passado recente. O gasto médio do fluxo turístico doméstico e internacional crescerá, mais ou menos, a uma taxa de $6 \%$ ao ano.

O gasto será diferenciado de acordo com o tipo de turista que SC conseguirá trazer: com o aumento dos turistas europeus, americanos e japoneses, os gastos se tornariam rapidamente maiores; buscando mais turistas no mercado latino-americano, os gastos ficariam nos níveis atuais, com um ligeiro crescimento.

O gasto dos turistas (nacionais e estrangeiros) aumentará a partir do desenvolvimento de novos produtos e serviços.

Além do aumento do número dos turistas, SC buscará o incremento do gasto médio dos turistas, oferecendo serviços de alto valor para turistas de alta renda, graças à oferta de eventos, nos âmbitos de: feiras, congressos e seminários; esportes náuticos; turismo de aventura; os esportes marinhos; outros esportes de elite (como o golf, o pólo, etc.).

\subsection{Ações}

\subsubsection{O marketing}

No futuro próximo, a promoção dos negócios turísticos terá que levar em consideração a evolução social, como nunca aconteceu no passado. Tendo conta que a sociedade será, cada 
vez mais emocional, as estratégias de marketing mais bem sucedidas serão aquelas que trabalharem com competência com: marketing de destinos; estratégia de marca; economia da experiência.

O marketing realizado pelo setor público facilitará o marketing das empresas mais inovadoras, em detrimento daquelas empresas de marketing tradicional, geral e centralizado.

A percepção de SC como destino turístico de férias de verão será mudada pela diversificação da oferta e pela criação de um calendário anual de eventos, com programações mensais de qualidade.

Um aspecto limitante do setor de turismo catarinense será a falta de iniciativas empresariais relevantes no âmbito do marketing.

O marketing do turismo será respaldado pela educação, isto é, contará com as escolas técnicas, que serão responsáveis pela formação de profissionais, tais como: taxistas, donos de lanchonetes e de restaurantes.

As estratégias de marketing mais bem sucedidas serão aquelas que investirem na comunicação baseada na vida saudável, natureza e ecologia. Além daquelas voltadas para a segmentação da oferta e, sobretudo, voltadas para públicos mais exigentes e de maior poder aquisitivo.

A sazonalidade diminuirá em função da utilização de estratégias de captação de segmentos distintos daqueles habituais das altas temporadas. Desse modo, os segmentos mais interessantes para SC serão: jovens casais; executivos e profissionais liberais; aposentados e terceira idade.

A estratégia de marketing business-to-business mais valorizada será a de "facilitação" (assistência prestada aos setores constituintes da indústria de viagens e turismo dentro de um país e nos outros países de origem de turistas).

Para desenvolver um forte marketing do destino serão organizados eventos (tênis, literatura, congressos) que atraiam público e mídia. Para isso, serão bem sucedidas as seguintes estratégias de marketing: uso da internet qualificada; revistas e meios de divulgação segmentados; divulgação seletiva em programas de TV (via cabo e aberta). 
O setor turístico de SC atuará, nos próximos anos, para mudar progressivamente seu público alvo, passando do "veranista” ao "turista evoluído”, que busca um produto mais articulado, mais rico, de melhor qualidade.

Santa Catarina encontrará dificuldades para a sua promoção turística no mercado internacional. Mas, diferentemente de outras cidades brasileiras, contará com um grande recurso para impressionar turistas europeus: as fortes comunidades italiana e alemã.

\subsubsection{Organização e profissionalização}

Os empreendimentos turísticos catarinenses terão como diferencial competitivo a especificidade, lastreada na cultura regional.

O formato do turismo alternativo ajudará no uso mais intensivo de tecnologia e na criação de empresas alternativas, com maior desenvolvimento de profissionais do turismo e ambiente. As relações e a sinergia entre os serviços turísticos e os produtos gastronômicos se fortalecerão nos próximos cinco anos.

No longo prazo, o turismo se transformará em uma indústria: caracterizada por empresas maiores, não pulverizadas. Haverá, também, maior e melhor comunicação entre as redes hoteleiras e nas relações inter-organizacionais (entre empresas diferentes). As empresas mais dinâmicas formarão parcerias com empresas do exterior, garantindo uma demanda antecipada da oferta qualificada.

Um dos maiores esforços para as empresas turísticas será a mudança da cultura do serviço, que deverá abandonar a lógica baseada nos “ativos” detidos pelas empresas (apartamentos, comida, equipamentos, etc.) e enfocar no produto desejado pelo cliente (a experiência de caminhar ao ar livre, de praticar um esporte náutico, de participar de uma festa popular, de ter um atendimento completamente excelente em um lugar extremamente refinado e confortável, etc.).

Um dos esforços principais do setor de turismo catarinense será - nos próximos anos - a acentuada formação: dos gerentes; dos funcionários; dos trabalhadores.

A evolução da profissionalização das empresas especializadas na área turística será gradativa, e estará relacionada, principalmente, aos segmentos da hotelaria e gastronomia. 


\subsubsection{As políticas públicas}

As políticas públicas representarão, nos próximos cinco anos, uma das fontes principais seja das oportunidades, seja dos riscos.

Na verdade, os possíveis fatores de desestímulo da vinda de turistas para SC serão: a falta de consolidação dos cenários de sustentabilidade; a fraqueza da capacidade de gestão políticoinstitucional.

As políticas públicas serão norteadas por três grandes condicionantes: cuidarão da preservação do patrimônio cultural, histórico, etc.; garantirão uma forte presença da dimensão social nas ações; apontarão para o aumento da entrada de divisas.

A principal tarefa de SC, nesse período, será a elaboração de um projeto para o futuro, com o objetivo de transformação de médio-longo prazos que possam ser compartilhados com o sistema econômico e se concretizar em ações para o desenvolvimento turístico.

O planejamento do desenvolvimento turístico será baseado no planejamento do uso do território (mobilidade, áreas industriais, comerciais, habitacionais, etc.). Todas as obras (saneamento e rodovias), sem planejamento, terão sua utilidade prejudicada. Para SC será necessário também um Plano de Turismo que identifique as possíveis áreas de desenvolvimento e favoreça a construção de um negócio ligado às especificidades de cada lugar. Serão desenvolvidas leis e regras mais coerentes, claras e melhor definidas em relação ao meio-ambiente (como licenças ambientais, para construção e exploração, de hotéis, campos esportivos, marinas, bares, restaurantes, etc.).

As políticas fiscais incentivarão e facilitarão a implantação de projetos com fins turísticos, principalmente, nas seguintes direções: criação de mapas e guias turísticos bem feitos e acessíveis; organização de sites em duas ou três línguas com links para reservas de vários serviços; melhoramento da sinalização turística; desenvolvimento de parques ecológicos; criação de novos roteiros culturais; promoção de esportes radicais.

As políticas sistêmicas mais necessárias para o setor de turismo, até o 2011, serão as seguintes: o planejamento estratégico do desenvolvimento sustentável do turismo; a melhoria do saneamento básico; a melhoria das garantias e da segurança para os investidores; a agilização do processo de criação de novos negócios; a maior clareza e coerência das leis; as políticas de incentivos fiscais à implantação de projetos com fins turísticos; a melhoria e a 
manutenção da sinalização; o respeito às diferenças; a implantação de portos com capacidade adequada.

A melhoria da qualidade dos serviços turísticos será estimulada pelas políticas públicas, nos próximos anos, seguindo dois caminhos: o primeiro será o caminho individual: os empreendedores e os funcionários das empresas turísticas usufruirão de atividades de formação e informação realizadas com suporte público; o outro instrumento apostará na dimensão coletiva, estimulando e apoiando a criação de uma rede de empresas que tem e desenvolve a qualidade dos próprios serviços.

Na realidade, nos próximos anos, o Estado lançará um plano de marketing e de divulgação para o turismo: dentro do Estado; em todo o Brasil; no exterior.

Entre as políticas de apoio e serviço, as mais necessárias para o setor de turismo serão: os investimentos em infra-estrutura turística; a formação dos empreendedores e dos gerentes públicos e privados; o apoio à criação de uma rede de empresas com qualidade de serviços; o incentivo ao desenvolvimento de uma oferta mais variada e ao longo de todo o ano; a criação de um plano de marketing para o turismo brasileiro; a difusão das "boas práticas" no campo da qualidade; a incubação dos projetos de pequenas e médias empresas; o apoio técnico e de marketing na implantação dos projetos; a criação de roteiros turísticos.

\subsubsection{Os impactos do turismo}

A maior parte do litoral de SC terá um futuro positivo graças à: preservação do meio ambiente; ocupação imobiliária organizada.

Os impactos ambientais do turismo serão decorrentes de: saturação de praias; ausência de saneamento. O resultado será o comprometimento das águas litorâneas, afetando a pesca e os produtos marítimos. As áreas degradadas e poluídas perderão espaço e fluxos turísticos.

Os negócios terão uma crescente auto-sustentabilidade econômica e financeira, que favorecerá uma evolução do setor de turismo. O cuidado para a sustentabilidade se difundirá: tanto no setor público; como no setor privado.

Haverá um impacto sócio-econômico positivo, pois que as comunidades vizinhas às áreas turísticas aprenderão a conviver de forma harmoniosa com o turismo, beneficiando-se do mesmo; o empresariado aplicará critérios básicos para o turismo sustentável; a comunidade 
será beneficiada também por meio de maior emprego, do pagamento de impostos, o que possibilitará a melhoria da educação, limpeza das ruas, saneamento básico e infra-estrutura.

\section{Conclusão}

O Delphi “O Futuro do Turismo em Santa Catarina” apresentou os pontos fundamentais de consenso sobre os aspectos fundamentais ligados à atividade turística no estado ou que tenham impacto importante sobre ela.

Tratando-se de metodologia prospectiva, o diagnóstico apresentado visa servir como base de orientação para desdobramentos que possibilitem e facilitem o planejamento de ações conjuntas para um futuro promissor.

O Fórum realizado para apresentação e debate sobre os resultados enriquecerá ainda mais o relatório final. Os resultados do projeto, são apresentados a seguir segundo uma matriz SWOT (Strenght, Weakness, Opportunities, Threats) do futuro do turismo em Santa Catarina, apresentada no Quadro 2.

Quadro 2 - Matriz SWOT representativa dos resultados até 2011

\begin{tabular}{|c|c|}
\hline Oportunidades & Pontos de força \\
\hline - a imagem positiva que o Estado possui; & $\begin{array}{l}\text { o posicionamento do Estado como destino } \\
\text { turístico diferenciado; }\end{array}$ \\
\hline $\begin{array}{l}\text { - os projetos, cada vez mais, "ecologicamente } \\
\text { corretos"; }\end{array}$ & $\begin{array}{l}\text { · a implantação efetiva e total do Plano Estadual } \\
\text { de Turismo; }\end{array}$ \\
\hline · melhoria na renda da população; & $\begin{array}{l}\text { - a preocupação com a profissionalização dos } \\
\text { trabalhadores do mercado; }\end{array}$ \\
\hline $\begin{array}{l}\text { · um bom índice de desenvolvimento } \\
\text { econômico, social, educacional; }\end{array}$ & $\begin{array}{l}\text { - a integração turística das regiões (para o turista } \\
\text { ter opç̃es simultâneas); }\end{array}$ \\
\hline - o crescimento do turismo no Brasil; & · a receptividade por parte da população local; \\
\hline $\begin{array}{l}\text { o aumento do turismo experiencial em todo } \\
\text { o mundo; }\end{array}$ & - a boa infra-estrutura de transportes e logística; \\
\hline $\begin{array}{l}\text { - o extraordinário patrimônio cultural e } \\
\text { natural de Santa Catarina; }\end{array}$ & $\begin{array}{l}\text { a capacidade de receber os mais modernos } \\
\text { navios da atualidade e os gigantes que estão } \\
\text { sendo construídos e operados: }\end{array}$ \\
\hline $\begin{array}{l}\text { - a crescente importância da responsabilidade } \\
\text { social nos projetos; }\end{array}$ & o turismo endógeno; \\
\hline $\begin{array}{l}\text { uma malha rodoviária que possibilita o } \\
\text { deslocamento nas diversas regiões. }\end{array}$ & $\begin{array}{l}\text { · consonância do Plano Estadual com Programa } \\
\text { de Regionalização de Turismo do Governo } \\
\text { Federal; }\end{array}$ \\
\hline
\end{tabular}




\begin{tabular}{|c|c|}
\hline & - a gastronomia local. \\
\hline $\begin{array}{l}\text { Ameaças } \\
\text { · a falta de continuidade das políticas públicas, } \\
\text { em virtude da mudança de governos; } \\
\text { · a destruição do “ativo” representado pelo } \\
\text { litoral; } \\
\text { · a miséria e a exploração/exclusão; } \\
\text { · as leis e regras incoerentes e confusas que } \\
\text { geram insegurança; } \\
\text { · a lentidão nas decisões e na liberação de } \\
\text { projetos; } \\
\text { · a falta de acompanhamento do crescimento } \\
\text { e desenvolvimento do setor; } \\
\text { · a falta de visão do poder público; } \\
\text { · os impostos altos; } \\
\text { · as condições financeiras dos brasileiros e } \\
\text { vizinhos; } \\
\text { · o nível de criminalidade. }\end{array}$ & $\begin{array}{l}\text { Pontos de fraqueza } \\
\text { · a falta de um posicionamento do Estado como } \\
\text { destino turístico diferenciado; } \\
\text { · a falta de um planejamento estratégico confiável } \\
\text { no turismo; } \\
\text { · a ausência de valorização do turismo para o } \\
\text { desenvolvimento do Estado; } \\
\text { · o baixo profissionalismo no setor; } \\
\text { · a aplicação inadequada das diretrizes e eixos } \\
\text { estruturantes dos Planos de Turismo; } \\
\text { · a ausência de profissionalismo nos órgãos } \\
\text { públicos de turismo; } \\
\text { · a ausência de uma busca permanente de } \\
\text { diferenciação da concorrência; } \\
\text { · a falta de visão dos empresários; } \\
\text { · a ausência de pesquisas eficazes e eficientes na } \\
\text { área; } \\
\text { · a ausência de um programa estadual voltado à } \\
\text { capacitação dos agentes institucionais de } \\
\text { Turismo. }\end{array}$ \\
\hline
\end{tabular}

A aplicação do Delphi como ferramenta se mostrou adequada e até inovadora para a elaboração de cenários no setor de turismo. Sua principal limitação é, sem dúvida, o custo, devido à necessidade de utilização intensiva de pesquisadores e da disponibilidade dos especialistas e debatedores. Entretanto, os resultados são importantes para servir de base para a tomada de decisão de ações e para realização de planejamento na área. Outra vantagem possível é que envolve diversos stakeholders possibilitando o consenso ou pelo menos a aceitação conjunta o que facilita o trabalho de planejamento posterior.

\section{Referências}

CORNELLIUS, P.; VAN DE PUTTE, A.; ROMANI, M. 2005. Three Decades of Scenario Planning in Shell. California Management Review. Vol. 48, n. 1, p.92-109.

FISCHER, A. L. 2001. Tendências que orientam as decisões dos formadores de opinião em gestão de pessoas no Brasil - RH 2010. Enanpad, n. 25. 
GIOVINAZZO, R., FISCHMANN, A. 2000. Delphi Eletrônico: uma experiência de utilização da metodologia de pesquisa e seu potencial de abrangência regional. In: COSTA, B., ALMEIDA, M. (coord.), Estratégia: perspectivas e aplicações. São Paulo: Editora Atlas.

GODET, M. 1993. Manual de Prospectiva Estratégica. Lisboa: Publicações Dom Quixote.

LANDETA, J. 1999. El metodo Delphi. Barcelona: Ariel.

LINSTONE, H.A., TURROF, M., 1975. The Delphi method, techniques and applications. Addison Wesley Publishing.

PORTER, M. 1986. Estratégia Competitiva: técnicas para análise de indústrias e concorrência. Rio de Janeiro: Editora Campus.

S3 STUDIUM. 2002. Cara Brasileira. Brasília: Sebrae.

UNISUL. 2006. O Futuro do Turismo de Santa Catarina - Previsões entre 2007 e 2011. Florianópolis: Universidade do Sul de Santa Catarina.

SANTOS, A. C. 2001. O uso do método Delphi na criação de um modelo de competências. Revista de Administração, Universidade de São Paulo, v. 36, n. 2, abr/jun, p. 25 - 32.

SERRA, F.; TORRES, M. C.; TORRES, A. 2002. Administração Estratégica: conceitos, roteiro prático e casos. Rio de Janeiro: Reichmann \& Affonso Editores.

VERGARA, S. 2005. Métodos de pesquisa em Administração. São Paulo: Editora Atlas.

\section{Recebido em: 12/03/2007}

Aprovado em: 12/04/2007 